\title{
El origen de los vetones en la historiografía española del siglo XX. ¿Implantación o formación?
}

\author{
Eduardo Sánchez Moreno **
}

En un momento en que la revisión critica y científica de la historiografía de nuestro pasado empieza a valorarse en su justa medida ${ }^{1}$, parece adecuado plantearse el examen diacrónico de la bibliografía histórica generada a lo largo de todo este siglo XX en torno al origen de una de las entidades étnicas de la Protohistoria Final que poblaron buena parte de la meseta occidental: los vetones.

Por atractiva que resulte, la aproximación al estudio de la configuración étnica y cultural de una población del pasado está cargada de riesgo y dificultad. Hablar de etnia, raza, pueblo, estirpe, comunidad, etc., es hoy en día adentrarse en un terreno resbaladizo, casi peligroso, sobre el que ideologías políticas, corrientes sociales y planteamientos filosóficos han creado un punto de discusión y reivindicación no exento en muchas ocasiones, y nuestra historia contemporánea tristemente nos lo sigue recordando, de enfrentamientos violentos. Al trasladar esta cuestión al pasado protohistórico de nuestra Península Ibérica, afortunadamente, la dialéctica, aunque también violenta con frecuencia, no rebasa el terreno del papel y la palabra, que no es poco.

* Universidad Autónoma de Madrid.

* Becario de F.P.I.-U. del Ministerio de Educación y Ciencia en el Departamento de Historia Antigua y Medieval y Paleogratia y Diplomática de la Universidad Autónoma de Madrid. Proyecto de Investigación PS92-0024.

Ahi están, fruto de este propósito, las Actas del / Congreso de Historiografia de la Arqueologia y de la Historia Antigua en España (ss.XVIII-XX), J. Arce y R. Olmos (Coord.); Madrid, 1991, y la reciente celebración del II Congreso de Historiografía, con el tema especifico de "La institucionalización de la Arqueología en España, ss.XVIII-XX”(Noviembre, 1995). 


\section{UNA CONSTANTE EN LA TRADICIÓN HISTORIOGRÁFICA: IMPLANTACIÓN DE LA ENTIDAD ÉTNICA.}

A partir de las escuetas referencias de autores clásicos (Strab. III, 1, 6; III, 3, 1; III, 3, 2; III, 3, 3; III, 4, 12; Plin., N.H., III, 19; IV, 112; IV, 113; y Ptol. II, 5,7 ) sobre la localización del pueblo de los vetones, los eruditos de fines del s. XIX e inicios del XX especulaban con la fijación de sus territorios y con la identificación de los escasos restos de yacimientos arqueológicos conocidos adscribibles a este grupo étnico (SÁNCHEZ MORENO, e.p.). En esta línea, mientras Gómez Moreno (1904) llevaba a cabo sus estudios por tierras de la alta Castilla, alguno de los doctos extremeños de aquella época, como M. Roso de Luna $(1901 ; 1904)$ o M. de Monsalud (1901), iniciaban los pioneros trabajos arqueológicos en la zona, en particular sobre lo que denominaban citanias de las poblaciones celto-lusitanas extremeñas. Eran los verracos y algunos de esos castros o citanias de la meseta occidental lo que más llamaba la atención a los investigadores, que no tardaron en precisar la filiación étnica de sus autores y pobladores. Así, mientras Gómez Moreno asigna a los vetones un origen ligur (1949, $37,80)$ siguiendo la inclinación de su época por la tesis ligur propuesta por H.d'Arbois de Jubainville $(1893,1894)$, A. Schulten los tacha de íberos (1914, 69-73).

La publicación en 1932 de La Etnología de la Península lbérica de P. Bosch Gimpera supone un hito en el repaso historiográfico que presentamos. El gran mérito del que fue uno de nuestros mayores prehistoriadores fue intentar relacionar el registro arqueológico con la evidencia lingüística y las alusiones de algunos autores latinos, como César, sobre las diferentes tribus de celtas y su expansión desde Centroeuropa, para sistematizar la entrada de tales grupos en nuestra Península en un esquema de correspondencia/dependencia cronológica, material, lingüística y étnica, de manera que quedara establecido el cuadro etnológico de nuestro poblamiento antiguo (BOSCH GIMPERA, 1932; 1944; 1974) ${ }^{2}$ (v. figura 1).

\footnotetext{
2 En el pensamiento de Bosch Gimpera queda bien patente su formación en Alemania (19111914). Como pone de manifiesto J. Cortadella, el prehistoriador catalán debe el interés por el tema etnológico a A. Schulten y bebe de la metodología que aprendiera con U. Schmidt y G. Kossina. En cuanto a la trascendencia de su obra, se subraya la real y efectiva descolonización de la investigación protohistórica a partir de él y la creación de una visión particular de la historia peninsular en la que los pueblos indigenas se convierten en eje y motor de los acontecimientos. En este sentido, para Bosch Gimpera la historia de España era el choque y la acción mutua entre una España indigena y una serie de superestructuras o interferencias venidas del exterior (CORTADELLA, 1991, 165, nota 31). Su espíritu se condensa en la siguiente sentencia: “L'element verament indigena dels pobles peninsulars no desaperegué per l'entrada dels que tenem un nóm historic i que
} 


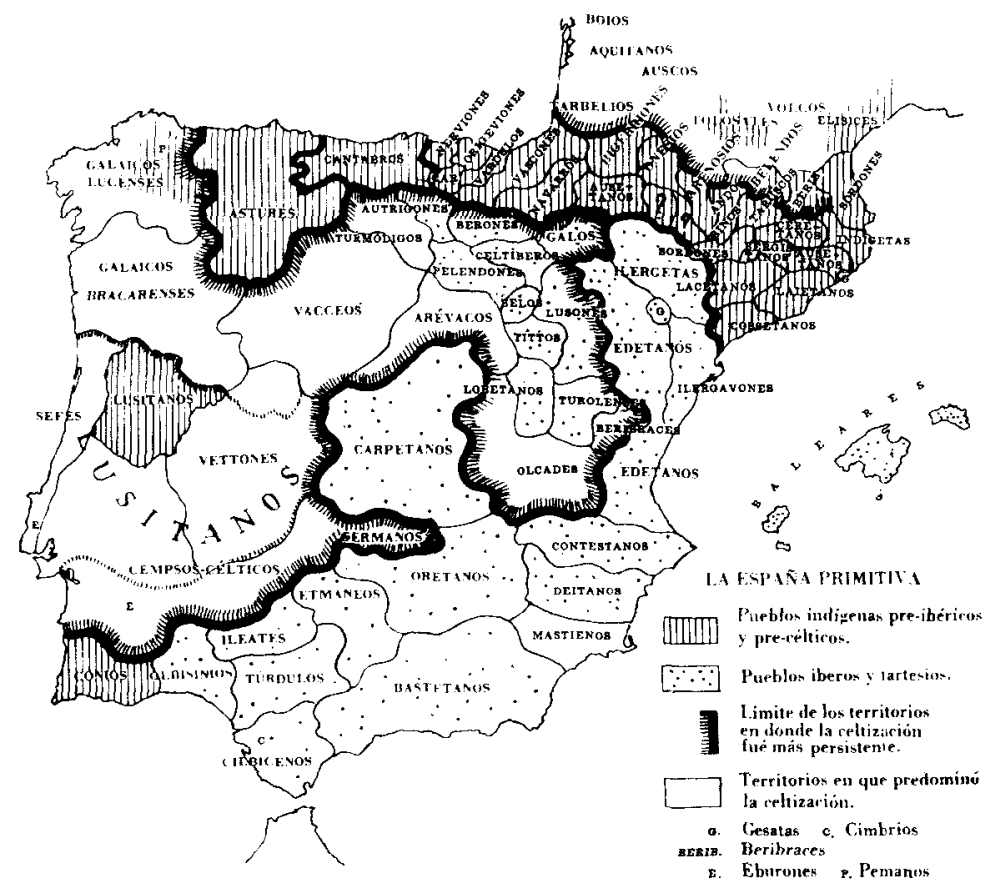

Figura 1. Los pueblos de la antigua Iberia, según Bosch Gimpera. (BOSCH GIMPERA, 1944, mapa VIII).

Paralelamente A. Schulten hacia lo propio, pero apoyándose con más fuerza en los testimonios clásicos (culminado en la enciclopédica obra de 1959). Nacia con ello la teoría invasionista de las oleadas célticas ${ }^{3}$.

dominarem més o menys el pais. Es mès, passat algun temp, els invasors acabarem fonent-se amb els indigenes, $i$ en molts llocs nuclis importants d'aquest degueren seguir intactes per molts temps». (BosCh GIMPERA, 1932, 4).

3 La interpretación de Bosch Gimpera se gesta a partir del estudio lingǘstico de $\mathrm{H}$. d Arbois de Jubainville $(1893,1894)$ que relaciona la expansión de celtas, ligures para él, con la Península Ibérica. La tesis ligur también fue defendida por A. Schulten (1914; 1922) basándose en un análisis de los textos clásicos y por Gómez Moreno (1949). Años después, J. Pokorny corrige a D'Arbois y sustituye la invasión ligur por la iliria, que precede a dos posteriores, la de celtas goidélicos y la de celtas britones (POKORNY, 1936; 1940). Seguidor de la tendencia iliria, aunque con un carácter mixto -uso del etnónimo ambrones- para la Península lbérica fue R. Menéndez y Pidal (1952). El estudio de los distintos grupos celtas en sus movimientos fue retomado por $H$. Hubert (1957). La confirmación de la invalidez de tales intentos propició que en la actualidad lingüistas y arquólogos avancen, la mayoría de las veces, por caminos separados.

En esos mismos años en que Bosch Gimpera y Schulten daban luz a las oleadas célticas se encuentran curiosas interpretaciones como la de L. Siret. Interpolando eclécticamente los versos 
En un primer momento Bosch Gimpera distinguía dos invasiones célticas, la primera con entrada en la Península a través de los Pirineos orientales hacia el cambio de era, identificable con la cultura de Campos de Urnas (Urnenfelder) hallstátticos - ya celtas para este prehistoriador-y con asiento en Cataluña y el Valle del Ebro (1932, 406, 424; 1936, 4245); y la segunda, la amplia entrada de centroeuropeos en el s.VI a.C. debida a presiones germanas en el Bajo Rin que les empuja hasta el centro y occidente de la Península, provocando su celtización (1932, 453-469). En lo que a nuestros vetones se refiere, en estas primeras obras Bosch Gimpera señala que no se trata de un pueblo céltico, tampoco ibérico, sino de raigambre indigena (cultura megalítica portuguesa superpuesta a una base indigena de la cultura central) anterior a la invasión céltica, que se ve, no obstante, afectado por ésta, hasta el punto de considerarlo un pueblo arrinconado en torno al Sistema Central, dominado primero por los celtiberos y después por los lusitanos (Bosch Gimpera, 1932, 533, 539540, 597).

Años después, el pensamiento de Bosch Gimpera (1942; 1944; 1950 51 ; 1952-53; 1974) evoluciona con respecto a sus primeras obras. Matiza algunos aspectos en la fijación de las oleadas celtas, sobre todo en relación al segundo gran movimiento en el que distingue tres grandes subgrupos o impulsos (v. figuras 2-3):

1) Celtas-germánicos de Westfalia, compuesto por varios pueblos, - cempsos, cimbrios, eburones...-, que penetran en los ss.VIII-VII a.C. hasta el Bajo Aragón, la meseta castellana, Extremadura y Portugal, dando lugar a la cultura arcaizante hallstáttica de Cogotas 1 y a algunas tribus como la de los berones y pelendones (BosCH GIMPERA, 1942, 75-77; 1944, 125-126).

2) Conglomerados de sefes-turones, a los que se unen otros pueblos celtas empujados por la presión germana como los nemetati/nemetes, boios, santones, bituriges, lingones, sesones, etc., que se establecerán en las llanuras del occidente meseteño, para alcanzar después León,

de la Ora Marítima de Avieno, con los hallazgos de alabardas de bronce de la cultura argárica, el hispanista belga habla de conquista armada de la Peninsula lbérica por parte de los celtas que vienen vía maritima después de invadir Irlanda y Escocia en plana Edad del Bronce hacia 13001200 a.C., configurándose como el "pueblo de alabardas celtas de El Argar" identificable con los Bastetianos o Mastetianos de las fuentes (SIRET, 1934, 90-91, 98-99).

Pocos años antes se había empezado a excavar uno de los castros más paradigmáticos de la meseta occidental, Las Cogotas (Cardeñosa, Ávila), y J. Cabré, su investigador, consideraba sus pobladores a "los celtas Saefes y Cempsi desde el S.VI hasta el IV a.C. y después a los celtas Vetones, acaso de estrato étnico ligur, en los ss.IV y III a.C." (CABRÉ, 1930, 111-112). 


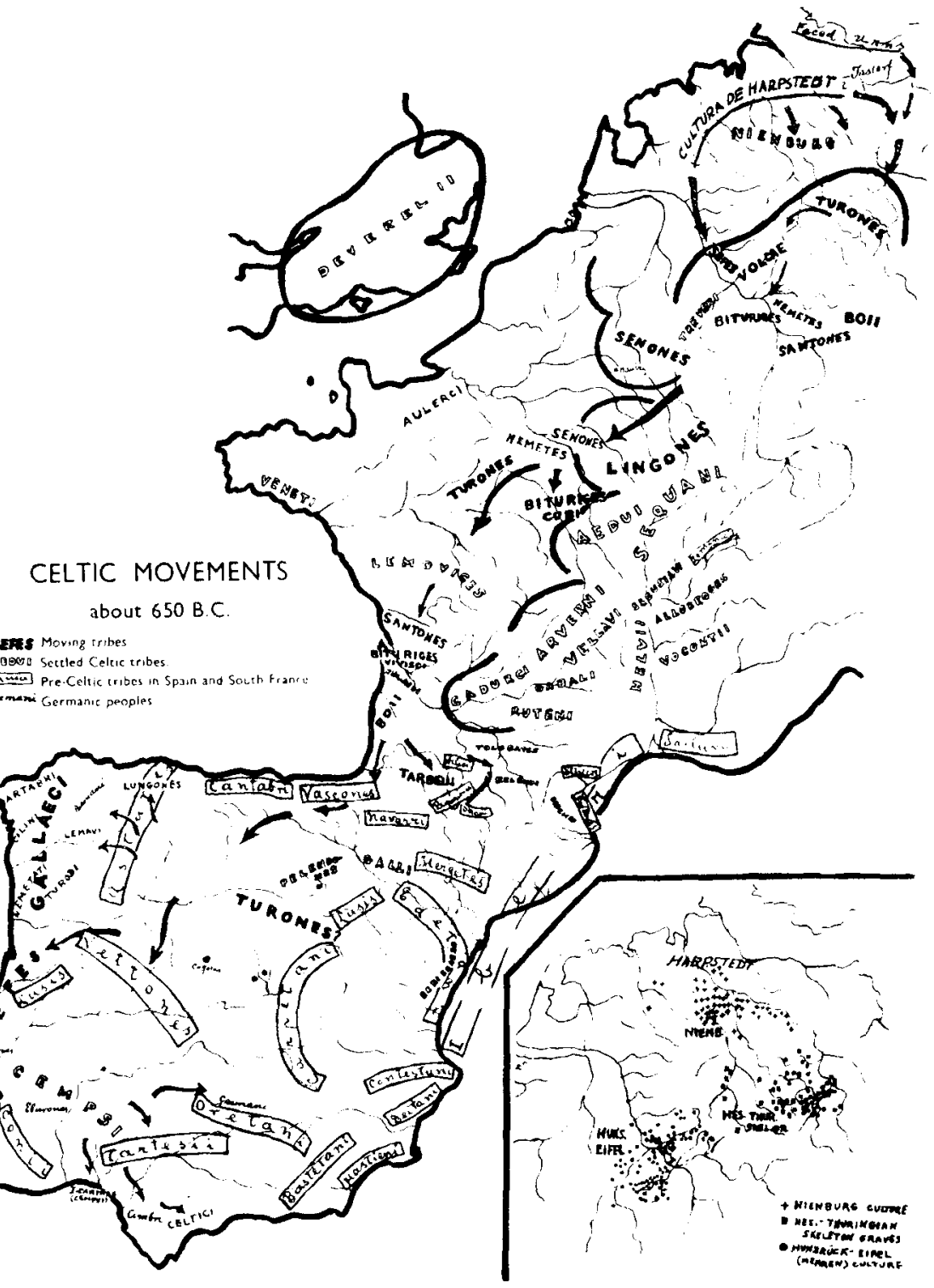

Figura 2. Conglomerado de Sefes-Turones y otros grupos celtas en su entrada a la Península Ibérica hacia el 650 a.C., según Bosch Gimpera.

(BOSCH GIMPERA, 1942, mapa III). 


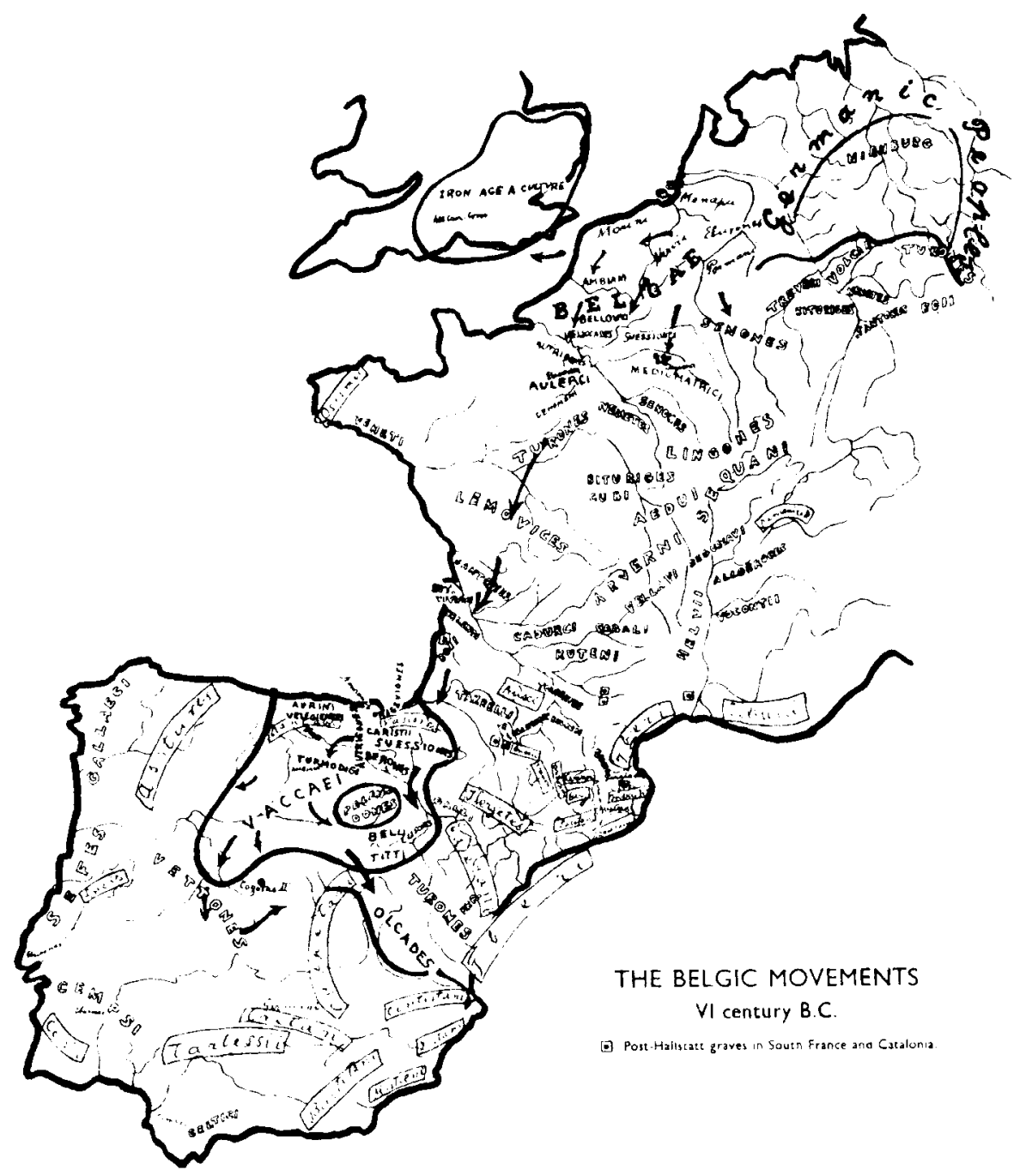

Figura 3. Movimientos de los celtas belgas posthallstátticos en el s. VI a.C., según Bosch Gimpera.

(BOSCH GIMPERA, 1942, mapa IV). 
Asturias, Galicia y el norte de Portugal poco antes del 600 a.C; parte de los cuales constituyen el antecedente de los históricos vetones conocidos siglos después (Bosch GimperA, 1942, 77-84; 1944, 128) (v. figura 2).

3) Celtas belgas, entre los que se encuentran suessiones, belovacos, nervios, ambianos, veliocasses, autrigones, caristios, etc. Éstos llegarían a la Península Ibérica en el primer tercio del s.VI a.C., y de ellos el grupo principal de belovacos, que con el tiempo se identificarán con los celtíberos de las fuentes clásicas, divididos a su vez en vascones, vacceos, arévacos, belos y titos - derivados cada uno a su manera de la misma raiz léxica de belovacos, según la argumentación de Bosch Gimpera- se extenderán hacia el interior peninsular dominando y arrinconando a las poblaciones de origen céltico anteriores: los arévacos a los pelendones en torno a la provincia de Soria, los belos y los titos harán lo propio con los lusones en la región del Jalón y los vacceos con el antecedente de los vetones a los que limitan a las altas cumbres del Sistema Central -Gredos, Gata- (Bosch Gimpera, 1942, 84-91; 1944, 130-132) (v. figura 3).

Así pues, a la hora de la adscripción étnica de los vetones, Bosch Gimpera cambia de opinión sosteniendo ahora que este pueblo sí estaba celtizado, aunque escondería un grupo indígena anterior $(1944,151)$. Culturalmente para toda la región vetona distinguen tres fases: Cogotas I, como la cultura hallstáttica más arcaica propia de la meseta; Cogotas II, cultura de los vetones celtas, desde el s.VI en adelante; y Cogotas III, cultura posthallstáttica vaccea, protagonizada por los vacceos que procedentes de la última oleada de celtas belgas someten a los vetones y se extienden sobre parte de su antiguo territorio en el s.lll a.C. (BOSCH GIMPERA, $1942,53,62-63)$.

La herencia de esta interpretación - hoy calificable de lastre, aunque en su momento supusiera una tesis innovadora y adecuada - se convirtió en axioma hasta hace bien poco y aun en nuestros días sigue estando de alguna forma presente, como pronto comprobaremos. En aquellos años, décadas de los 30-50, Almagro Basch, tras un detenido análisis estrictamente arqueológico, ofrecía un nuevo modelo para el problema de las invasiones célticas en nuestro país. Reconoce, como había hecho Bosch Gimpera, el origen de lo celta en la Cultura de los Túmulos de la Edad del Bronce, que dará lugar a los Campos de Urnas (Urnenfelder), pero a la hora de explicar su expansión por el occidente y sur de Europa, en lo que toca a la Península Ibérica, se separa del prehistoriador catalán y en lugar de hablar de varias oleadas invasionistas, prefiere contemplar una única, confusa y amplia, que se inicia con los Campos de Urnas indoeuropeos hacia el 800 a.C., y se acompaña de continuas infiltraciones hasta el s. VI 
a.C. (Almagro BASCH, 1935, 184; 1944, 110-111, 267; 1947-48, 330); otorga Almagro un gran predominio en el terreno arqueológico al elemento invasor celta sobre el indígena local $(1944,256){ }^{4}$. Al mismo tiempo, A. García y Bellido, sin referirse a los tan traidos y llevados Campos de Urnas, diferenciaba de nuevo dos invasiones indoeuropeas: una primera en el s.VIII a.C., testimoniada por la cerámica de Cogotas, Numancia I y Roquizal del Rullo, y otra segunda en el s.VI a.C., que da lugar a la cultura posthallstáttica, identificable con los celtas belgas de Bosch Gimpera (Garcia y Bellido, 1941, 289).

Otro nuevo esquema defiende Martínez Santa-Olalla, con claro afán revalorizador de lo céltico $(1946,21)$. Para este autor, a tres invasiones indoeuropeas pre-célticas de variados elementos étnicos y culturales que se adentran por los Pirineos entre los años 1000-700 a.C. aproximadamente (1946, 67-68), sucede la llegada de celtas que darán lugar a las culturas del Hierro céltico I (desde 650 a.C.) y Hierro céltico /I (1946, 80, 101), creadores de los grandes castros. Además Santa-Olalla cree en una invasión tardia en la Península de celtas britones de la cultura de La Tène B centroeuropea $(1946,102)$, retomando las hipótesis de Pokorny o Hubert, algo que había rechazado Bosch Gimpera que no veía más invasiones después de la de los celtas belgas del s.VI a.C. (Bosch GIMPERA, 1942, 73-74; 1944, 132). En el antropólogo e historiador J. Caro Baroja también encontramos rastro de las invasiones; aunque se muestra escéptico en cuanto a las cuestiones ligur e iliria (CARO BAROJA, 1976, I, 79-80, 85), afirma que hacia el 650 a.C. grupos de celtas introdujeron el hierro y una lengua en España y luego distingue otras oleadas célticas entre el 350-250 a.C., con foco de expansión en los cursos superior y medio del

4 Este enfoque se enmarca dentro de la idea más amplia de unidad étnica ancestral de España que Almagro Basch construye, hijo de su época, bajo el argumento de la homogeneidad etnológica o racial primigenia, y en detrimento de unas nacionalidades descualificadas, que sirva, en último término, como un argumento más a la idea de unidad nacional (CORTADELLA, 1989, 17, 24); a pesar de que para la protohistoria hispana distingue, dentro de ese marco nacional unitario, una España interior, noroccidental, hostil, de economia ganadera y vida rural y una España costera, levantina-meridional, permeable, de economía agraria y vida urbana (CORTADELLA, 1989, 20. 21). A fin de cuentas Almagro Basch es uno de los máximos representantes de la tendencia historiográfica de la época franquista, caracterizada por la exaltación patriótica y la penetración de la corriente germana nacionalista, por familiaridad potítica y deuda académica. En este contexto ideológico cabe situar también a J. Martinez Santa-Olalla, J. de la Mata Carriazo, T. Ortego, B. Taracena, A. Tovar en su primera etapa, J.M de Navascués, etc. Para estos aspectos acerca de la situación de la investigación arqueológica y de la Historia Antigua durante el franquismo véase Diaz-Andreu, 1993 y Prieto, 1979, y para la personalidad de algunos de estos autores, RodriguezPuÉatolas, 1986, I.

Sin duda alguna, queda contrastado el carácter de la tradición particularista, regionalista, que presenta Bosch Gimpera frente a la visión unitarista que defiende Almagro Basch. 
Rin y Danubio (Caro Baroja, 1976, I, 87-88). No obstante es uno de los primeros en preguntarse por las distintas posibilidades de contacto cultural y en contemplar los efectos de una difusión multidireccional (con especial atención a la aculturación) analizando los caracteres locales anteriores y no sólo los efectos invasionistas $(1976, \mathrm{I}, 95-96 ; 1986,98){ }^{5}$. Tocante a los vetones, los clasifica como grupo fundamentalmente pastoril con amplia presencia de elementos célticos, similares a los celtiberos (1976, I, 168) dentro de la segunda gran área cultural de las tres en que divide la Península Ibérica: area cultural de la Meseta y Occidente (1976, I, 98; 1986, 47).

Enmarcable en la misma corriente invasionista, pero con un enfoque deducido del análisis lingüístico, A. Tovar cree en una entrada primera de indoeuropeos pre-celtas desde fines de la Edad del Bronce, con un estrato lingüístico identificable con los hidrónimos con la raiz -nt- (ej: Salmantica) y otros restos lingüísticos como páramo, a los que no atribuye un nombre concreto pero los hace constituidores de las capas de población más antiguas, que en las serranías centrales estarían representadas por vetones, carpetanos, además de pelendones, cántabros o astures (Tovar, 1957, 78-82; 1967, 242). Acepta asimismo, como Bosch Gimpera, una segunda entrada, ya de celtas, en varias oleadas culminadas con los celtas belgas que arrinconan a los pueblos llegados con anterioridad, caracterizada en el plano lingüístico principalmente por el uso de nombres con el sufijo -briga (1957, 82; 1967, 243-247). Asimismo Tovar (1949a, $96-118 ; 1949 b$ ) pone en relación la evidencia de gentilidades o grupos familiares, ampliamente testimoniados entre los vetones, con los invasores primeros que quedan acorralados después por los celtas, llegados posteriormente, en las zonas montañosas marginales (la idea es mantenida en Albertos, 1975, 19-20, 52; González Rodríguez /Santos, 1984, 53-54; González Rodríguez, 1986, 108 y en Solana Sainz, 1991); sin embargo, hoy ya se ha demostrado que entre los celtíberos más avanzados del valle del Ebro, y en el borde oriental de la meseta, la indicación del grupo familiar (gentilidad) era elemento básico de la fórmula onomástica en los textos prerromanos, lo que excluye su atribución única a un grupo indoeuropeo pre-celtibérico (DE Hoz, 1986, 91-98; 1993, 390). En cualquier caso, para

\footnotetext{
"(...) ¿Cuándo y cómo los elementos, los rasgos culturales que se registran en un momento se incorporan, se asocian unos a otros? ¿Aquéllos que aparecen con un carácter complejo, llegaron al lugar que los encontramos con tal carácter, o éste es producto de una elaboración in situ? ¿En que grado la difusión de un elemento cultural supone la difusión de otros y en qué relación puede estar con la expansión de una lengua o raza, con la adaptación al medo? (...)" (CARO BAROJA, 1976, l, 100).
} 
Tovar queda clara la colosal trascendencia de la indoeuropeización de toda la mitad noroeste de la Península: "Con la sucesiva fijación de preceltas y celtas se europeiza la Meseta para siempre y ella se convierte en el elemento activo por excelencia en la Historia de España" (Tovar, $1967,251)$. En la misma línea de este gran lingüista se sitúa la opinión de una de sus mejores discípulas, Ma.L. Albertos Firmat (1975), y de la amplia escuela de lingüistas que creó, que llega hasta nuestros días con la teoría de F. Villar, que detecta tres estirpes lingüisticas indoeuropeas: 1) el Antiguo europeo (alteuropäisch) anterior al I milenio a.C. del que sólo nos quedan algunos restos en la toponimia e hidronimia, 2) el Lusitano, indoeuropeo pre-céltico con arcaicas formas en $/ p$ / inicial que se da entre vacceos, vetones y lusitanos, y 3 ) el Celtibérico con rasgos ya más conocidos y abundantes (-briga, -dum/dunum) introducidos a través de los pasos pirenaicos en los ss. VIII-VII a.C. (VILLAR, 1991, 441-464).

J. Maluquer de Motes, como B. Taracena, sigue en líneas generales el mecanismo de las oleadas invasionistas indoeuropeas y su sistematización debidas a Bosch Gimpera, aunque es consciente de la complejidad de esas invasiones con elementos muy variados (MALUQUER, 1952, 10-13, $134 ; 1955,248-253)$. Los vetones, por lo tanto, presentan un carácter indoeuropeo fuera de toda duda, de honda raíz hallstáttica, indoeuropea, aunque conservarían un sustrato indígena fuerte de remoto origen meridional que explicará el matiz iberizante de ciertos aspectos de su cultura material. Procederian de una oleda indoeuropea anterior a la de los vacceos, siendo acorralados por éstos hasta que los romanos restablezcan sus antiguas fronteras en beneficio de los vetones. Sin embargo, se trataría de un grupo de patente y peculiar personalidad (MALUQUER, 1952, 25, 130-132; 1955, 253-254). A. Molinero, un veterinario abulense con vocación de arqueólogo e incansable estudioso de los castros de su provincia, integra las sinopsis de Bosch y Santa-Olalla respecto a las distintas oleadas y es fiel a la interpretación hallstáttica del origen étnico de los vetones dada por su contemporáneo Maluquer (Molinero, 1958, 52).

La confusión derivada de la maraña de oleadas, cronologías escaladas, invasiones, referencias a pueblos protagonistas - ligures, ilirios, ambrones, celtas, indoeuropeos, ...-, etc., propuestas en la primera mitad de este siglo, lleva a algunos autores a establecer cuando menos curiosas interpretaciones sobre la formación etnológica de algunos pueblos prerromanos, como la que realiza Sayans Castaños a finales de los años 50 sobre los pobladores de la Alta Extremadura, nuestros vetones, como «ligures o pueblo de los ambrones, descendientes de los centum centroeuropeos que llegan a la Península como un pueblo fundamentalmente de pastores de cerdos", que dará nombre a la tierra sobre la que se asientan, 
denominándose así la comarca extremeña Ambrascum o Ambrasco (SAYANS, 1957, 177-178).

A pesar de todo, en las siguientes décadas los modelos tradicionales de invasiones y celtización de la Península siguieron desarrollándose. Ahí están por ejempio las observaciones de Gómez Tabanera, que integra varios elementos para hablar una vez más de dos oleadas, una hacia 750 y otra en 650 a.C. $(1967,340)$, o de J.M ${ }^{a}$ Blázquez. Para éste los vetones, como también los carpetanos, astures, cántabros y pelendones, como pobladores indoeuropeos más antiguos hablarian una lengua indoeuropea pre-céltica y serian empujados por las oleadas posteriores de celtas belgas (BLAZQUEZ, 1974, I, 76). De esta forma retoma la interpretación, gestada en Bosch Gimpera, del expansionismo vacceo de raíz celtibérica -etnia derivada del grupo de celtas belgas- sobre los vetones hasta el punto de someterlos territorial y culturalmente, pues según este autor la cultura meseteña de Cogotas - se refiere a lo que nosotros entendemos hoy por Cogotas $11-$, que pertenecería a los vacceos, se superpone a la de Boquique, identificable con los vetones, de manera que muestra el proceso de franca expansión/solapamiento de los primeros sobre los segundos en el s.III a.C. (BLÁzQuez, 1962, 427; 1974, I, 207).

La misma huella se deja sentir en obras más cercanas en el tiempo. Lomas sigue hablando de invasiones indoeuropeas, estableciendo continuos paralelos con culturas centroeuropeas sin atender al sustrato autóctono (LOMAS, 1980, 18, 27-28); admite la presencia de ilirios, ligures, cempsi, sefes, cynetes, sin apenas dudar y, lo que es peor, adscribiéndoles registros arqueológicos $(1980,55-56)$ y elementos lingüísticos sin ninguna dificultad (1980, 58-77), manteniendo la anacrónica metodología de los años 30 y $40^{6}$. Por descontado, piensa en una hegemonía de vacceos sobre vetones -llegados en las primeras oleadas junto a Beribraces, Sefes, Cempsi y pelendones $(1980,93)-$, incluso como élite aristocrática o minoría dirigente que se impone sobre los vetones, con un horizonte cultural que le es propio, el segundo nivel de Cogotas; asi lo testimoniarian, por ejemplo, las ricas tumbas de guerreros de La Osera o Las Cogotas (LOMAS, 1980, 30, 91-93).

\footnotetext{
6 Cae este autor, además, en importantes contradicciones, tal y como hemos argumentado en otra ocasión: asi, por ejemplo, en unos momentos identifica el hecho lingüistico con el hecho material, tachándolo de fundamental (LOMAS, 1980, 58), para decir luego todo lo contrario, que "el hecho lingüistico es, o puede ser, absolutamente diferente del hecho cultural" (1980,61), o que "los hechos lingüisticos tienen que ser resueltos desde la lingüistica , y cualquier estratigrafía lingüistica basada en nuestros conocimientos arqueológicos sólo conduce a un enrarecimiento de sus primordiales objetivos" $(1980,66)$, a pesar de que él mismo opera de forma opuesta.
} 
Uno de los motivos para esta argumentación, estriba en las citas de Polibio (III, 14,9$)$ y Livio $(21,5)$ que señalan a Salmantica como ciudad vaccea en el 220 a.C., cuando la expedición de Aníbal hasta esa ciudad y Arbucala; frente a esto, siglos después, Ptolomeo (II, 5-7) a mediados del s.ll d.C., cuando enumera las once ciudades vetonas, señala entre ellas a Salmantica. Esta divergencia de las fuentes, de forma enlazada con la idea de las sucesivas oleadas célticas, sirvió de apoyo en la interpretación del expansionismo de los vacceos sobre los vetones, hasta el punto de determinar que Salmantica/Helmantica, en origen núcleo de ámbito vetón, fuera conquistada por los vacceos en la época de su dominio hasta que con la llegada de los romanos éstos restituyeron el territorio primigenio a los vetones (así, para plena época romana, Ptolomeo de nuevo adscribe Salmantica como vetona) en un intento de debilitar la fuerza del mundo celtibérico -entre ellos, los vacceos - a costa de favorecer el resurgimiento de los pueblos oprimidos por los celtiberos, como nuestros vetones (LOMAS, 1980, 93) ${ }^{7}$. Como ya tuvimos ocasión de indicar en otro trabajo más extenso (SÁnchez Moreno, 1995), proponemos desechar de una vez esta hipótesis interpretativa y achacar la base de su error a dos puntos principales:

1) Malentender y aplicar incorrectamente el concepto de territorio y dominio político para estos momentos y pueblos, en lugar de hablar, como proponemos, de área variable de expansión e influencia, término mucho menos comprometido (SÁnchez MoREno, e.p.).

2) La incoveniencia de dar validez y acomodar la información de momentos tardios (Livio, Ptolomeo...) para periodos mucho más anteriores como el s.lll a.C.; acentuada en este caso por el hecho de utilizar con una misma intencionalidad a dos fuentes cronológica y conceptualmente bien distintas, como la más histórica de Polibio o Livio y la puramente geográfica y tardía de Ptolomeo, que se sirve de los etnónimos sencillamente como orientación geográfica y provincial para mediados del s.ll d.C. y sin ninguna carga histórica o documental del momento prerromano.

Por todo ello, pensamos que en torno a la cuestión de la ocupación del territorio norte de los vetones por parte de los vacceos hasta

De nuevo hay que remontarse a Bosch Gimpera para encontrar el arranque de tal exégesis $(1932,531-532)$, cultivándose desde él, y gracias a él, en la bibliografía posterior (Maluquer, 1952, 131-132, 137; 1956, 30-31, 97; 1958, 99-100; Bejarano, 1955, 118; Molinero, 1958, 54; BLAzOUEZ, 1962, 427; 1974, 207, 210, ROLDAN, 1971, 97; LozANO, 1973, 113; SALINAS, 1979, 74; Gonzalez Rodriguez/Santos, 1984, 53-54; Lopez Monteagudo, 1983, 158-159; 1989 , $43-44$, etc.). 
Salmantica al menos (dualidad de las fuentes: Salmantica vacceaSalmantica vetona), hoy debe ser entendida más como un asunto de reorganización de fronteras al sur del Duero, siguiendo una esquematización /estructuración natural de los límites y fronteras romanos (MANGAS, 1992, 255), que como un reflejo de conquista o expansión de un pueblo prerromano sobre otro y que como una restauración/deuda posterior romana sobre los vetones. $\mathrm{O}$, al menos, nos resulta insuficiente aceptar que tal expansión y dominio de los vacceos sobre los vetones quede evidenciado simplemente por el dato de Salmantica vaccea en unos autores y vetona en otros.

Por lo demás, el referido trabajo de Lomas (1980) es un ejemplo más de 10 que estamos contemplando en este bosquejo historiográfico: el tratamiento de la cultura de un pueblo como un conjunto importado, que llega ya formado del exterior, con un sello invasor, y en el que no hay opción a la observación del sustrato cultural arqueológico local ni a la teorización de fenómenos de aculturación o bifocalidad siquiera ${ }^{8}$.

Prácticamente lo mismo se puede decir de sintesis celtófilas como la de Tarradell, que reconoce también la irradiación de los vacceos sobre los vetones (TARRADELL, 1980, 159), la más monográfica pero también deudora de viejos postulados tradicionales de Salinas de Frías (1982, 23-25), el trabajo de Fernández Gómez, que vuelve a la añeja codificación de tres oleadas de invasiones, relacionando los vetones con la etnia de los eburones matizados después en el s.VI a.C. por los celtas belgas, para los que asigna el concepto, heredado de Bosch Gimpera, de cultura posthallstáttica (FERNÁNDEZ GómEz, 1986, 934-938), o, por ejemplo, el manual de Montenegro et alii $(1989,212,227)$ en el que se toman en consideración las distintas invasiones indoeuropeas peninsulares y se aplica a los vetones un carácter de población residual de dificil entronque con la etnia indoeuropea, o bien un trabajo del año 1991 de Solana Sainz, que persiste en mantener la secuencia de dos entradas de pueblos celtas: una primera oleada, los grupos de montaña, que viene protagonizada por cántabros, astures, carpetanos, pelendones y vetones, y una segunda, pueblos de llano, que hablaban la lengua celtibérica occidental y que se corresponde con los arévacos, autrigones, turmogos, belos, titos y vacceos (SOLANA, 1991, 13, 23), etc.

\footnotetext{
* Esta tendencia difusionista y tradicional al mismo tiempo queda perfectamerite definida en frases como "el suelo absorbe y nacionaliza al invasor" (TARACENA, 1952, 296).
} 
INDOEUROPEOS, HALLSTÁTTICOS, CELTAS, CELTAS BELGAS, CELTIBBEROS, POSTHALLSTTÁTICOS,.... O EL EMBROLLO QUE NO CESA

Tras la exposición de esta parte eminentemente descriptiva llega el momento de cuestionarse bajo una óptica más actualizada la problemática celta, sobre todo en algunos aspectos hoy claramente superados como el de la teoría invasionista de las distintas oleadas, y los flujos y reflujos que autores y tendencias se empeñan en alimentar. Es indudable que el tema de los celtas o el más genérico de lo indoeuropeo, después de haber pasado por etapas de sobrevaloración y rechazo, tiene hoy de nuevo un atractivo incuestionable.

La herencia de las viejas premisas de Bosch Gimpera, aunque todavía presentes en obras relativamente recientes como acabamos de ver y en la corriente germanista que trabaja sobre la protohistoria de nuestra Península y que mantiene, en general, esos preceptos invasionistas paralelizables culturalmente con Centroeuropa (SANGSMEISTER, 1960; SCHULE, 1969; 1979; KALB, 1979; 1990; LENERZ-DE WILDE, 1981; 1991 o STARY, 1983), ha sido convenientemente puesta en tela de juicio y superada por el avance investigador de los últimos años. Especialmente de un tiempo hacia acá la bibliografía al respecto ha sido prolija y las síntesis y trabajos sobre el tema genérico de los celtas se han sucedido en Europa (FILIP, 1962; Kruta, 1977; Kruta et alii, 1993; Cunliffe, 1988; Collis, 1989; Mallory, 1990; RenfreW, 1990; I Celti, 1991; Eleure, 1992; James, 1993; etc., etc.) y en España (Almagro Corbea, 1987, 1992, 1993; Ruiz Zapatero, 1993; Blasco, 1989; Marco Simón, 1990; Villar, 1991; De Hoz, 1992; BerRoCAL, 1995; KURTZ, 1995; LORRIO, 1995; y otros muchos, además de los Coloquios de Lenguas y Culturas Paleohispánicas celebrados en 1974, 1976, 1980, 1985, 1989, 1994; los Simposia sobre Celtíberos de 1987, 1989, 1991; la exposición "Celtíberos" de 1988 en Zaragoza con publicación incluida, Burillo et alii, 1988; los cursos monográficos sobre Celtas en el M.A.N., 1991, en El Escorial, 1992: curso de verano de la Universidad Complutense -Almagro Corbea, dir., 1993-, en Cuenca organizado por la U.I.M.P., -e. p.-; la publicación monográfica de Revista de Arqueologia, Los Celtas en la Península lbérica, 1991; o los debates generados en torno al problema de los indoeuropeos a partir de trabajos concretos ${ }^{9}$; etc., etc.).

9 Especialmente sobre la obra ya comentada de Renfrew (1990) han caido variadas recensiones y reflexiones críticas en un interesante foro de opinión. Asi, Ruiz-Gálvez, M./Ruiz Zapatero, G., "Cielos, los arios atacan de nuevo!", Arqritica, 1991, n², 11-14; Gorrochategui, J., "El puzzle indoeuropeo", Arqrítica, 1991, $\mathrm{n}^{\circ}$ 2, 14-16; de Hoz, J., "Arqueología del lenguaje sin lágrimas... 
No es ésta la ocasión para profundizar en el estudio del fenómeno céltico, pero sí queremos exponer una serie de conclusiones que nos ayudarán a orientar el análisis sobre la formación cultural de los vetones. De entrada hemos de reconocer que hoy el concepto de celta es una confusión de lengua, fuentes históricas y datos arqueológicos (Collis, 1993) y que por celtas no se debe identificar a un pueblo histórico concreto y unívoco - menos aún en la Península lbérica-, sino que en todo caso el término pondría en relación, sin implicar una hermandad étnica o cultural de primera línea, a diferentes grupos con ciertos elementos culturales emparentados, resultado de un remoto tronco común difuminado por los siglos y por la complejidad del desarrollo cultural e histórico, pero con una personalidad bien diferenciada (BLASCO, 1989, 18; RUIZ ZAPATERO, 1993, 51; KURTZ, 1995) (v. figura 4). De hecho, en los últimos tiempos va

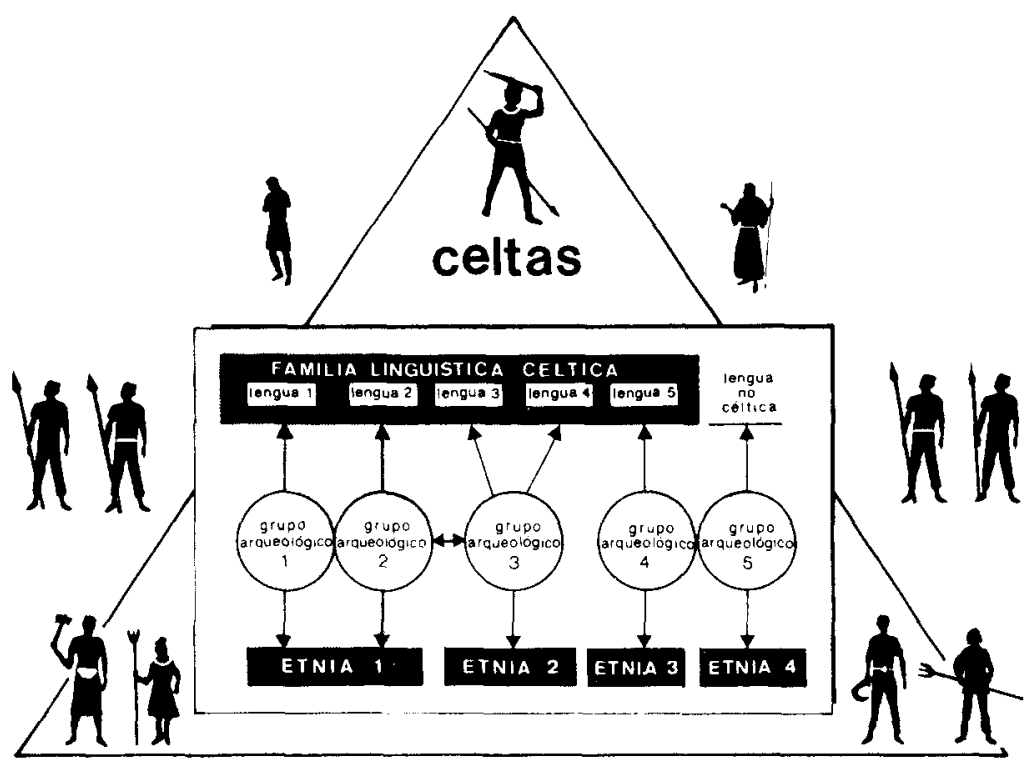

Figura 4. Diagrama de la complejidad de relaciones entre lengua, grupo arqueológico y étnia, y el simplismo de la construcción uniforme del concepto de los celtas que se ha venido superponiendo a esa realidad compleja, según Ruiz Zapatero. (RUIZ ZAPATERO, 1993, 53, FIG. 8). 
ganando fuerza el modelo explicativo anglosajón de lo indoeuropeo que se ha dado en llamar celticidad acumulativa. Introducido por Hawkes (1973) para Gran Bretaña y ampliado por Renfrew (1990), este planteamiento aboga por un remoto origen de la indoeuropeización en el Neolítico, extendiéndose con la agricultura en el VII milenio a.C. una primera lengua indoeuropea indiferenciada en un complejo proceso acumulativo con distintas evoluciones y contactos que cristalizaría, tras un estadio intermedio proto-céltico, en las distintas lenguas y entidades célticas del I milenio a.C.

Partiendo de un supuesto parecido, con necesarias transformaciones y particularidades, Almagro Gorbea ha adaptado un modelo para explicar la celtización de la Península. Distingue este autor un primer nivel protocéltico evidente desde la transición del Bronce Final al Hierro I, caracterizado por variados elementos (rasgos lingüísticos indoeuropeos pre-celtas relacionables con el lusitano, ritos y creencias como ofrendas fluviales, cultos acuáticos, costumbres como la hospitalidad, la exposición de cadáveres a los buitres, etc.), con poblaciones pre-gentilicias, extendido por el norte, centro y occidente de la Península y anterior al mundo céltico clásico; - este panorama más o menos homogéneo explicaría ciertas afinidades que presentan los pueblos históricos que habitaron esas regiones, como carpetanos, vetones, lusitanos, cántabros, galaicos, etc.- (ALMAGRo GORBEA 1990, 560; 1992, 7-20; 1993, 128-146). De este sustrato surgiría la posterior cultura celtibérica que en torno al s.VI a.C. y desde su área nuclear en el alto Tajo y Jalón protagonizaría un fenómeno de progresiva celtización en mosaico - dentro de un marco de aculturación y evoluciónde buena parte del territorio peninsular sobre todo hacia el norte y occidente (cultura vetona de Cogotas II, Beturia céltica, cultura castreña del Noroeste...), de forma irregular y predominantemente dependiente de las élites guerreras, en un medio-ambiente pastoril, puesto de manifiesto en una serie de elementos homogéneos característicos (necrópolis de incineración, armas típicamente celtibéricas, testimonios lingüísticos como los topónimos en -briga o Seg-, sistemas defensivos, rasgos de religión celta, etc.). Este proceso tendería hacia una homogeneización -celtiberización - de todo el territorio que finalmente quedaría interrumpida por la acción romana (ALMAGRo CORBEA, 1990, 560-562; 1992, 20-24; 1993, 146160; la argumentación de Almagro es asumida por uno de sus últimos discípilos: LoRRıO, 1995, 95-108) ${ }^{10}$.

10 En un reciente trabajo L. Berrocal retoma, acaso con excesivo eclecticismo, el modelo de celticidad acumulativa y el ensayo constructivo de lo protocelta y lo celta de Almagro Gorbea, en 
Esta tesis, asentada sobre un serio trabajo documental y arialítico de varios años, es susceptible de ciertos matices críticos según nuestra opinión. En primer lugar, ¿cómo se forman tales elementos en la Celtiberia?, ¿por qué precisamente ahí, en esa área nuclear y no en otra, pues, como dice Almagro, se da el mismo sustrato protocéltico en toda la región indoeuropea peninsular?, ¿por qué el proceso de formación que acontece en el corazón celtibérico, correcto y factible en cuanto a su descripción, no puede producirse al mismo tiempo o algo después en otras áreas?. ¿Es tan evidente esa influencia de la Celtiberia en el resto de territorios desde inicios de la Segunda Edad de Hierro en el campo arqueológico y en las demás fuentes y testimonios?, ¿no seria posible hablar de un florecimiento o de una celtización peninsular (Hierro II) con varios focos regionales más o menos paralelos en el tiempo, en lugar de un único origen y de una expansión desde el mismo al resto con posterioridad?. En caso de que existiera tal expansión, ¿de qué tipo seria?, ¿significaria un control político, una implantación poblacional, una aculturación material simplemente? Por otra parte, ¿existe una homogeneización cultural en las regiones indoeuropeas peninsulares en la Segunda Edad de Hierro tan manifiesta de verdad? En definitiva, poniendo Almagro Gorbea un hiato tan claro y diferenciado entre el sustrato protocéltico y el de la celtización a

la reflexión personal que realiza sobre los indoeuropeos, célticos y celtibéricos en el territorio extremeño (BERROCAL, 1995). Llega este autor a la conclusión de que, a un proceso de indoeuropeización acumulativa iniciado al menos en época calcolitica con el vaso campaniforme y que traeria consigo la formación de jefaturas individualizadas, sucede en la segunda mitad del ler milenio a.C. un complejo fenómeno de celticidad acumulativa, acelerado por la minorización del factor orientalizante-tartésico a partir del s.V a.C., al que acompañan aportes poblacionales desde el alto Duero, el Ebro inicial y la meseta oriental (i...vacceos en su opinión!) que se desplazan hacia el sur en relación con las explotaciones ganaderas a larga distancia y con los recursos mineros de hierro. Según Berrocal, “estos últimos conformarán los célticos del Sudoeste, poblaciones que hablaban una lengua celta y procedian de los vacceos, celtiberos en un sentido muy laxo" (BerRocal, 1995, 143). Por último, a finales de s.ll a.C. llegarian a la Beturia céltica contingentes estrictamente celtibéricos -citeriores: belos, titos-, parece que élites guerreras en busca de control territorial (BERROCAL, 1995, 141-142).

Al referirse a los vetones por una parte señala que "en el territorio cacereño, con el desarrollo de una cultura material prerromana de clara adscripción de Cogotas II, que podriamos asimilar a los vetones de las fuentes clásicas (...), vienen a reflejar la expansión meridional, quizá poblacional, de gentes de las tierras del Duero medio sobre el cauce del Tajo" (BERROCAL, 1995, 135-136) , para posteriormente hablar de «un importante aporte poblacional que incidirá (...) sobre el territorio cacereño, desde los castros vetones del Duero medio..." (BERRocAL, 1995. 143). El territorio cacereño al que se refiere este autor (la mayor parte de la provincia de Cáceres, a excepción del extremo occidental que es ámbito lusitano) forma parte natural del área de expansión vetona (SANCHEz MORENO, e.p.), mientras que la región del Duero medio es, sin duda alguna, la esfera nuclear del poblamiento vacceo (y no la zona más oriental, en torno a las cuencas altas del Duero y del Ebro, como afirma BERROCAL, 1995, 143, que en realidad es el corazón de la Celtiberia). 
partir de la región celtibérica ¿no está retomando, de manera quizá involuntaria o disfrazada, la dinámica difusionista de las oleadas o distintos momentos configuradores de culturas, aunque corrigiendo el sentido radical de invasión por un proceso de aculturación o transformación, acertadamente reconocido por el autor (Almagro CorbeA, 1990, 560; 1993, 146$147,156)$ ?

En otro orden de cosas no nos parece apropiado el uso desmedido del término de celta/s (ALMAGRo CORBEA, 1992; 1993; BLASCO, 1989; LóPEZ MONTEAGUDO, 1977; 1989; MARCO SIMÓN, 1990, etc.), sin ninguna matización, para los pueblos prerromanos de la Península lbérica (una revisión con denuncia crítica sobre su empleo en KALB, 1993). Resulta más viable utilizarlo para cuestiones lingüísticas ${ }^{11}$. Se ha propuesto para la Península sustituir el concepto de celta/céltico por el de celtibérico con el sentido genérico, locativo, no étnico, de los celtas de Iberia (Dominguez Monedero, 1983, 211, 217; 1988, 26; CeRDEÑo, 1992, 481). El vocablo aludiría en un principio a los celtíberos que habitaban en torno al río Ebro/lber, celtíberos citeriores y ulteriores (BURILlo, 1993, 224-236), pero cuando Iberia pasa a designar a toda la Península, según la aplicación y extensión que del término realizan los autores griegos (DOMinguez MONEDERO, 1983), por celtibérico se identificará únicamente a la entidad histórica de los pueblos celtas por autonomasia de la meseta oriental (LORRIO, 1995, 107-108), los primeros de que se tuvo noticia, mientras que el resto de pueblos de raiz indoeuropea que se mencionan fuera de esta área nuclear conocidos con posterioridad, recibirán el nombre de sus propias organizaciones tribales para diferenciarse entre sí (DOMinguez Monedero, 1988, 27). Para el caso de los vetones, el etnónimo personaliza el nombre de una tribu de transmisión más antigua, pero su etimología es hoy por hoy inexplicable pues, según Untermann, no conocemos el léxico ni la gramática de la lengua dentro de la cual el etnónimo tuvo su origen (UNTERMANN, 1992, 23-24, 32) ${ }^{12}$. En conclusión, a la hora de aludir a los

1. Efectivamente muchos mantienen que la acepción más válida y objetiva de celta en sí es la linguistica: celta es quien habla la lengua celta (TOVAR, 1986; Collis, 1989; BLASCO, 1989, 19; Renfrew, 1990, 194-195, 201; MARCo Simón, 1990, 23-38; VILLAR, 1991; Cerdeño, 1992, 477, 480481; De Hoz, 1993, 360; Kurtz, 1995, 16, 29; etc.). Pero para la Peninsula Ibérica las dificultades, si cabe, son mayores, habida cuenta que ni siquiera en el plano lingüístico existe una uniformidad, toda vez que encontramos varios registros lingüisticos indoeuropeos: al menos un lusitano, pre-céltico, y un celtibérico más clásico (Almagro Corbea/Lorfio, 1987; De Hoz, 1983; 1992; 1993, 384, 386; VILLAR, 1991, 464-466; además de en ToVAR, 1986; Gorrochategui, 1987; 1993, 419, 422; 1994, 13, etc.); aunque Untermann (1984; 1987) no ve el lusitano como lengua ni más antigua ni diferenciada del celtibérico sino emparentada directamente, consecuencia probable de una misma y única entrada de indoeuropeos, celtas...

12 Por lo tanto hay que dudar de particulares etimologías del vocablo vetones, como la que establece Sayans $(1957,189)$ que lo pone en relación con Vera, Viriato, etc. y cree que significa- 
pobladores de la Hispania indoeuropea somos partidarios de rechazar hablar de celtas como tales en la Península, y en su lugar preferimos la referencia a celtibéricos, en sentido genérico o geográfico (J. DE HOz, 1988, es partidario de utilizar la expresión de hispano-celta para referirse a todo aquello que no puede garantizarse que sea celtibérico, pero sin excluir que lo sea), y con significación cultural o étnica la del nombre correspondiente de la tribu o entidad, en nuestro caso el etnónimo de vetones.

De cualquier forma hoy parecen superados del todo algunos viejos preceptos, como el de la identificación de Campos de Urnas del Noreste con el componente céltico, que ha quedado definitivamente desvinculado (RuIz ZAPATERO, 1985; LoRRIO, 1995, 107) al igual que se rechaza el término de Campos de Urnas para la Meseta (ALMAGRo CORBEA, 1986-87, 42; 1987, 329 ). Por otra parte, como ya se ha dicho, ha quedado convenientemente refutada la tesis difusionista de las oleadas de invasiones celtas (ALMAGRO Corbea, 1986-87, 39; Sayas/López Melero, 1991, 81-83; Ruiz Zapatero, 1993, 55; etc.), lo cual, sin embargo, no excluye reconocer otras posibilidades de movimientos que no conlleven necesariamente el matiz de invasión. En este sentido, Almagro Gorbea señala diferentes tipos de migraciones favorecidas por el desarrollo tecnológico, económico y demográfico, según los casos, como son los movimientos de jóvenes guerreros, en ritos de iniciación y por tanto con una motivación social o ideológica que se les escapa a los autores clásicos, los movimientos en busca de botín y riqueza por motivos económicos, las movilizaciones en las que se llega a tomar ciudades u ocupar territorios, los movimientos más complejos de migración familiar que denomina modelo de expansión discontinuada (ALMAGRo CORBEA, 1987, 333-335), además de contactos por vía marítima -atlántica o mediterránea- con Centroeuropa (BLASCO, 1989, 33), etc. Por lo tanto correr definitivamente la página tan leida de las teorías invasionistas no significa negar que existieron amplios movimientos de población de distinta naturaleza ${ }^{13}$ (MARCO SIMÓN, 1990, 109-112; VILLAR, 1991, 466),

ria algo semejante a "gentes del aro o del anillo", como habitantes de los valles serranos de la alta Extremadura, cercados por colosales arcos y anillos como el zócalo de Gredos.

Muy recientemente $A$. Canto ha sugerido la relación etimológica con la raíz del griego étos y del latín vetus, identificable con "los viejos, los antiguos", deducción que vincula con la idea tradicional de ver a los vetones como el resto de una oleada indoeuropea muy antigua (CANTO, 1995, 155).

13 Esta idea ya se la habia planteado A. Garcia y Bellido (a propósito del pasaje de César, B.C., I, 51 en que un grupo pequeño de galos emigra hacia llerda) en una exquisita reflexión: "¿Cuántas emigraciones habrá habido como éstas y más importantes que por su carácter pacifico, tranquilo, "anónimo" pudiéramos decir, no han dejado huella histórica apreciable? ¿Por qué pensar siempre en las "grandes invasiones", en las migraciones violentas y asoladoras concebidas un poco al modo como los románticos se figuraban la invasión de los bárbaros?" (GARCiA Y BELLIDO, 1950, 491). 
aunque son muy difíciles de percibir en el registro arqueológico al mostrar muchas veces una continuidad estratigráfica que desmiente la existencia de esos fenómenos.

\section{UN NUEVO ENFOQUE: ETNOGÉNESIS Y FORMACIÓN}

El abuso descomedido para la Península Ibérica de conceptos como Campos de Urnas, período de Hállstatt, cultura de La Tène, mundo posthallstáttico, celtas, celtas belgas, indoeuropeos, indoeuropeos pre-célticos... etc., (introducidos por los pioneros sistematizadores de nuestra Prehistoria, bajo la dependencia de la perspectiva arqueológica del celtismo centroeuropeo; KALB, 1993) ha creado una ambigua maraña terminológica que sólo ahora parece que empieza a ser desenredada. Consideramos que es desde una posición abierta a los efectos de aculturación, de asimilación de diferentes elementos culturales fruto de variados contactos, influencias y desarrollos, pero contemplados sin olvidar el proceso de formación interna local, de la que podremos extraer resultados más completos y válidos (Almagro CorbeA, 1987, 321; 1990, 560; 1993, 146-147, 156; Almagro Corbea/Ruiz Zapatero, 1992, 475; Ruiz Zapatero, 1993, 55; GonzÁlez WAGNER, 1993; etc.).

Así pues, la idea de implantación con que la historiagrafía general hasta no hace mucho atendia al estudio de una entidad étnica, como algo impuesto y venido de fuera ya configurado, debe ser corregida por la de formación, entendida como un amplio y complejo proceso etnogenético en el que intervienen variados elementos a lo largo del tiempo y del espacio. Aplicar este análisis al grupo cultural vetón para poder sistematizar desde cuándo podemos hablar de vetones y cómo se desarrolla su proceso formativo, implicaria llevar a cabo desde una perspectiva diacrónica una visión de las transformaciones sucesivas del registro arqueológico (en combinación con otros datos informativos como los deducidos de los textos clásicos y los testimonios lingüístico-epigráticos; SÁNCHEZ MORENO, 1995, 265-282), que, obviamente, excedería los límites de estas páginas. Sin embargo, y a modo de epílogo, avanzamos que, en nuestra opinión, la realidad que las fuentes greco-romanas nos transmitieron como vetones para los últimos siglos antes de nuestra era no debe ser aprehendida como una cultura y un pueblo de origen foráneo, instaurado a inicios de la Segunda Edad del Hierro, sino que responde más bien al resultado de un complejo proceso de acrisolamiento iniciado con seguridad al menos desde el Bronce Final, potenciado y conformado en el transcurso de los siglos posteriores del ler milenio a.C. Surge por tanto, debido en parte al ca- 
rácter de vía de comunicación y transmisión que posee este territorio ${ }^{14}$, de la interacción de un sustrato local del Bronce Medio con una serie de variados aportes culturales, atlánticos, orientalizantes del Mediterráneo, indoeuropeos -entendidos estos últimos como un lento y complejo fluir de elementos de remota filiación continental, difíciles de precisar y definir, evolucionados y transformados con los siglos (SAYAS/LOPEZ MELERO, 1991, 94, 101; SAYAS, 1993, 197), y no como entrada de oleadas invasionistas- y más tardíamente ibero-turdetanos, celtibéricos y lusitanos, que a fuerza de matizar, transformar y caracterizar un proceso de desarrollo histórico, configuran una base cultural que sólo muchos siglos después podremos corroborar como identidad vetona.

\section{BIBLIOGRAFIA}

ALBERTOS FIRMAT, Màn.L., (1975); “Organizaciones suprafamiliares en la Hispania Antigua", Studia Archaeologia, 37.

ALMAGRO BASCH, M., (1935); "El problema de la invasión céltica en España, según los últimos descubrimientos", Investigación y Progreso, 9, pp.180-184.

AlMAgRO BASCH, M., (1944); "La invasión céltica en España", en Menéndez Pidal, R. (dir.), Historia de España, 1-2, Madrid, pp.3-278.

AlmAGRO BASCH, M., (1947-48); "Sobre la fijación de las invasiones indoeuropeas en España", Ampurias, $9-10$, pp.326-330.

14 Esta fisonomia del espacio vetón como tierra abierta, marco transicional y lugar de contacto cultural amplio y variado, desde el Bronce Final y con un momento álgido en el Periodo Orientalizante, queda atestiguado por una serie de aspectos, interrelacionados entre si, entre los que destacan: a) el desarrollo de un entramado, de raiz protohistórica, de estratégicas vias naturales de comunicacion, determinado por el medio físico de este espacio; b) las evidencias mate. riales de productos alóctonos - acompañados de ideas, modas, influencias, técnicas... - llegados por intercambio comercial o por otros mecanismos, y que enlazan esta región meseteña occidental con ámbitos, atlánticos, continentales y mediterráneos, especialmente estos últimos en una proporción a la que no se habia prestado mucha atención, y c) significativos rasgos lingüisticos en los que, si bien lo indoeuropeo es predominante, también participan de cierta raiz meridional todavía no suficientemente conocida y valorada.

Son éstos, factores que ayudan a comprender el complejo proceso de formación etnogénica y cultural, iniciado al menos desde el Bronce Final, que tendrá como resultado la identidad cultural y étnica que las fuentes clásicas nos trasmiten bajo el etnónimo de vetones, para un momento inmediatamente prerromano. Resultado en el que no sólo toma parte el componente indoeuropeo o continental, fuerte y contrastado en varios terrenos (onomástica personal, toponimia y teonimia, dentro de los rasgos lingüísticos; ciertos elementos de cultura material, etc.), sino tambièn el aporte mediterráneo (SÁnCHEz MOREnO, 1995). De esta forma, debe desligarse el estudio de esta región meseteña del modelo céltico, al que tradicionalmente, más que vincular, se ataba; sin que signifique esto, como ya se dijo, dejar de reconocer deudas y relaciones con el mundo continental, existentes a toda luz. $Y$, asimismo, rebasando el falaz esquematismo de la teoria de las oleadas invasionistas, somos partidarios de congelar ideas como la expansión de vacceos sobre vetones o la restauración original de éstos posteriormente por parte de Roma en agradecimiento a un supuesto comportamiento vetón filorromano... En nuestra opinión, ni arqueológica ni literariamente las fuentes de información, analizadas globalmente, sancionan estas interpretaciones. 
Almagro Corbea, M., (1986-87); “Los Campos de Urnas en la Meseta", Zephyrus, 39-40, pp.31-47.

Almagro Corbea, M., (1987); "La celtización de la Meseta: estado de la cuestión", Actas del I Congreso de Historia de Palencia, I, Palencia, pp.313-344.

Almagro Corbea, M., (1990); "Segunda Edad del Hierro. La celtización de la península tbérica y los pueblos del occidente: vetones y lusitanos", en Domínguez Ortiz, A. (dir.), Historia de España, I, Barcelona, pp.554-563 y 570-574.

Almagro Corbea, M., (1992); «El origen de los celtas en la Península Ibérica. Protoceltas y celtas", Polis, 4, pp.5-31.

Almagro Corbea, M., (1993); "Los celtas en la Peninsula lbérica: origen y personalidad cultural", en Almagro Gorbea, M. (dir.), Los Celtas: Hispania y Europa, Madrid, pp.121-173.

Almagro Corbea, M., Lorrio, A., (1987); "La expansión céltica en la Península lbérica: una aproximación cartográfica", / Simposium sobre Celtiberos (Daroca, 1986), Zaragoza, pp.105-122.

Almagro Corbea, M., Ruiz Zapatero, G., (1992); "Paleoetnologia de la Península Ibérica Reflexiones y perpectivas de futuro», en Almagro Gorbea, M./Ruiz Zapatero, G. (Eds.), Paleoetnologia de la Peninsula Ibérica, Madrid, pp.469-499.

D'ARBols de Jubainville, H., (1893); "Les celtes en Espagne", Revue Celtique, 14, pp.356379.

D'Arbois de Jubainville, H., (1894); “Les celtes en Espagne», Revue celtique, 15, pp.1-19

BEJARANO, V., (1955); "Fuentes antiguas para la historia de Salamanca", Zephyrus, 6, pp.89. 119.

BerRocal Rangel, L., (1995); "Indoeuropeos, célticos y celtiberos en el territorio extremeño", Extremadura Arqueológica IV. Arqueologia en Extremadura: 10 años de descubrimientos, Mérida, pp.123-149.

Blasco Bosqued, M․C., (1989); «El fenómeno céltico", Los celtas en el Valle Medio del Ebro, Zaragoza, pp.15-37

BlAzQUez MARTiNeZ, J.Má., (1962); "La expansión celtíbera en Carpetania, Bética, Levante y sus causas (ss.llt-II a.C.)", Celticum, 3, pp.409-428.

Blázouez Martínez, J.Ma ., (1974); Ciclos y Temas de la Historia de España. La Romanización. I y $\|$, Madrid.

Bosch GIMPERA, P., (1932); Etnología de la Peninsula Ibérica, Barcelona.

Bosch Gimpera, P., (1936); "Los celtas de la Cultura de las Urnas en España". Anuario de Cuerpos de Archiveros, Bibliotecarios y Arqueólogos, 3, pp.2-45.

Bosch Gimpera, P., (1942); "Two celtic waves in Spain", Proceedind of the British Academy, 26, Londres, pp.3-126.

Bosch Gimpera, P., (1944); El poblamiento antiguo y la formación de los pueblos de España, México.

Bosch Gimpera, P., (1950-51); "Les mouvements celtiques. Essai de reconstritution", Études celtiques, Paris, 5, pp.353-400.

BOSCH GIMPERA, P., (1952-53), "Les mouvements celtiques. Essai de reconstitution", Études celtiques, Paris, 6, pp.72-126 y $329-355$.

Bosch Gimpera, P., (1974); Paletnologia de la Peninsula lbérica. Colección de trabajos sobre los celtas, iberos, vascos, griegos y fenicios, Graz.

Burillo Mozota, F., (1993); "Aproximación a la arqueología de los celtiberos", en Almagro Gorbea, M., (dir.), Los celtas: Hispania y Europa, Madrid, pp.223-253.

Burillo, F., Pérez, J.A., De Sus, M‥J., (1988); Celtiberos, Zaragoza.

Cabré Agulló, J., (1930); "Excavaciones de Las Cogotas (Cardeñosa, Ávila). I, El Castro», Memorias de la Junta Superior de Excavaciones y Antigüedades, Madrid.

Canto de Gregorio, A.M"., (1995); "Extremadura y la Romanización", Extremadura Arqueológica, IV. Arqueologia en Extremadura: 10 años de descubrimientos, Mérida, pp.151-178.

Caro Baroja, J., (1976); Los pueblos de España, I y ll, Barcelona, 2a edic. (1 ${ }^{\text {a }}$ edic. 1946).

Caro Baroja, J., (1986); Ciclos y Temas de la Historia de España. España Antigua (conocimiento y fantasia), Madrid.

A.A.V.V., (1991); Los Celtas en la Peninsula Ibérica. Monográfico de la Revista de Arqueologia, extra $n^{\circ} 5$, Madrid.

A.A.V.V., (1991); / Celti, Milán. 
CerreñNo, Má.L., (1992); "Necrópolis célticas, celtibéricas e ibéricas: una visión de conjunto", Congreso de Arqueologia Ibérica: las Necrópolis, Madrid, pp.473-508.

Collis, J., (1989); La Edad del Hierro en Europa, Barcelona.

Collis, J., (1993); "Los celtas en Europa", en Almagro Gorbea, M., (dir.), Los celtas: Hispania y Europa, Madrid, pp.63-76.

Cortadella y Morral, J., (1988); “M. Almagro Basch y la idea de la unidad de España», Studia Historica, 6, pp.17-25.

Cortadella y MORRAL, J., (1991); “La formación académica de Bosch Gimpera: de la filologia griega a la protohistoria peninsular". Historiografia de la Arqueología y de la Historia Antigua en España ss.XVIII-XX, Madrid, pp.161-166.

CUNLIFFE, B., (1988); Greeks, Romans and Barbarians, Spheres of interactions, Londres.

DiAz ANDREU, M., (1993); «Theory and ideology in archaeology: Spanish archaeology under the Franco régime", Antiquity, 254, pp.74-82.

Dominguez MOnedero, A.J., (1983); "Los términos Iberia e iberos en las fuentes greco-latinas: estudio acerca de su origen y ámbito de aplicación", Lucentum, 2, pp.203-224.

Dominguez Monedero, A.J., (1988); "En torno a algunos aspectos socio-económicos de la cultura vaccea: estado de la cuestión’, Caesaraugusta, 65, pp.23-76.

Eleure, C., (1992); L Europe des Celtes, Paris.

FERNANDEZ GómEZ, F., (1986); Excavaciones arqueológicas en El Raso de Candeleda (Ávila). I y 11. Ávila.

FILIP, J., (1962); Celtic civilitation and its heritage, Praga.

GARCIA $\checkmark$ BELLIDO, A., (1941); El hombre prehistórico y los origenes de la humanidad, Madrid.

GARCÍA Y BELLIDO, A., (1950); "Algunos problemas relativos a las invasiones indoeuropeas en España", Archivo Español de Arqueología, 23, pp.487-496.

Gómez MOReno, M., (1904); "Sobre la arqueología primitiva en la región del Duero", Boletín de la Real Academia de la Historia, 65. Madrid. (también publicado en Miscelaneas, 1949. pp.131-140).

Gómez Moreno, M., (1949): Miscelaneas, Madrid.

Gómez TABAnera, J.Mà., (1967); "Los pueblos antiguos de la Península lbérica", en Gómez Tabanera, J.M .., (ed.), Las raices de España, pp.303-349.

GonzAlez Rodriguez, M… (1986); Las unidades organizativas indigenas del área indoeuropea de Hispania. Vitoria-Gasteiz.

GonzAlez Rodríguez, Mª.C. SANTOS YANGUAS, J., (1984); "Arrinconamiento de poblaciones en época prerromana y altoimperial ${ }^{2}$. Actas de las /I Jornadas de Metodologia y Didáctica de la Historia (Historia Antigua), Cáceres, pp.47-57.

GONZALEZ WAGNER, C., (1993); "Metodología de la aculturación. Consideraciones sobre las formas de contacto cultural y sus consecuencias", en Mangas, J. y Alvar, J., (Eds.), Homenaje a J.M. Blázquez, vol.l, Madrid, pp.445-464.

Gorrachategui, J., (1987); "En torno a la clasificación del lusitano", Actas IV Coloquio sobre Lenguas y Culturas paleohispánicas de la Peninsula lbérica, Vitoria, pp.77-91.

GorRACHATEGUI, J., (1993); "Las lenguas de los pueblos paleohispánicos", en Almagro Gorbea, M. (dir.), Los Celtas: Hispania y Europa, Madrid, pp. 409-429.

Gorrachategul, J., (1994); "La lengua de las poblaciones prerromanas del área indoeuropea", en González Rodríguez, Ma.C./Santos Yanguas, J., (Eds.); Revisiones de Historia Antigua, 1. Las estructuras sociales indigenas del norte de la Peninsula lbérica. Revisiones de Historia Antigua, I, Vitoria, pp.13-21.

HaWKES, C.F.C., (1973); "Cumulative Celticity in pre-Roman Britian", Étude Celtique, 13, II, pp.607-628.

Hoz, J. de, (1983); "Las lenguas y epigrafías prerromanas de la Península Ibérica", Unidad y pluralidad del mundo antiguo. Actas del VI Congreso Español de Estudios Clásicos, Madrid, pp.351-396.

Hoz, J. de. (1986); "La epigrafía celtibérica", Reunión sobre epigrafia hispánica de época romano-republicana, Zaragoza, pp.43-102.

Hoz, J. de, (1988); "Hispano-celtic and Celtiberian", en Mac Lennan (ed.); Proceedings of the First North American Congress of Celtic Studies, Ottawa, pp.191-207.

Hoz, J. de, (1992); "The Celts of the Iberian Peninsula", Zeitschrift für Celtische Philologie, 45, pp.1-37.

Hoz, J. de, (1993); "Testimonios lingüísticos relativos al problema céltico en la Península Ibérica", en Almagro Gorbea, M. (dir.), Los Celtas: Hispania y Europa, Madrid, pp.357-407. 
Hubert, H., (1957); Los Celtas y la expansión céltica hasta la época de La Tène, México.

JAMES, S., (1993); Exploring the World of the Celts, Londres.

KALB, P., (1979); "Die Kelten in Portugal", // Coloquio sobre Lenguas y Culturas prerromanas de la Peninsula lbérica (Tübingen, 1976), Salamanca, pp.209-223.

KALB, P., (1990); "Zum Keltenbegriff in der Archäologie der Iberischen Halbinsen", Madrider Mitteilungen, 31, pp.338-347.

KALB, P., (1993); "Sobre el término celta en la investigación arqueológica de la Peninsula Ibérica", en Untermann, J.NVillar, F. (Eds.); Actas del V Coloquio sobre Lenguas y Culturas Prerromanas de la Península Ibérica (Colonia, 1989), Salamanca, pp.143-157.

Kruta, V., (1977); Los Celtas, Madrid.

Kruta, V., Frey, O.H., Raftery, B., Szabo, C., (1993); The Celts, Londres.

KuRTz, W.S., (1995); "Lo céltico en el contexto de la arqueología europea", Celtas y Túrdulos: la Beturia, Cuadernos Emeritenses, no 9, Mérida, pp.9-48.

LENERz-DE WILDE, M., (1981); "Keltische Funde Aus Spanien", Archäologische Korrespondenzblatt, 11, pp.314-319.

LENERZ-DE WILDE, M., (1991); Iberia Celtica, Stuttgart.

LOMAS, F.J., (1980); "Origen y desarrollo de la cultura de los Campos de Urnas", "Las fuentes históricas más antiguas para el conocimiento de los celtas peninsulares", "Pueblos celtas de la Península Ibérica", "Instituciones indoeuropeas", en Historia de España Antigua, I. Protohistoria, Madrid, pp.13-51, pp.53-81, pp.83-110 y pp.111-126, respectivamente.

Lopez Monteagudo, G., (1977); “Apéndice. Los celtas de la Peninsula Ibérica”, en Kruta, V., Los Celtas, Madrid, pp.163-206.

Lopez Monteagudo, G., (1983); “Notas sobre los verracos hispánicos”, Homenaje al Profesor M. Almagro Basch, III, Madrid, pp.151-159.

López Monteagudo, G., (1989); Esculturas zoomorfas celtas de la Peninsula lbérica, Madrid.

LORRIO, A. J., (1995); "Celtas y celtiberos en la Península Ibérica", Celtas y Túrdulos: la Beturia, Cuadernos Emeritenses, n9, Mérida, pp.77-126.

Lozano Velilla, A., (1973); "Tipología de las estelas y la población de Hispania", Revista de la Universidad Complutense, 86, pp.89-114.

Maluouer de Montes, J., (1952); "Los pueblos de la España céltica", en Menéndez Pidal, R. (dir.), Historia de España, 1-3, Madrid, pp.1-299.

MaLuqueR DE MONTES, J., (1955); "El proceso histórico de las primitivas poblaciones peninsulares, \|», Zephyrus, 6, pp.241-255.

MaluQUer de MONTES, J., (1956); Carta arqueológica de España. Salamanca, Salamanca.

Maluquer de Montes, J., (1958); El castro de Los Castillejos de Sanchorreja, Salamanca.

MANGAS MANJARRÉS, J., (1992); "Ciudades antiguas de la provincia de Salamanca (s.lll a.C. Diocleciano)", I Congreso de Historia de Salamanca (1989), Salamanca, I, pp.251-268.

MALLORY, J.P., (1990); In search of the Indoeuropeans, Londres.

MARCO SimÓN, F., (1990); Los celtas, Madrid.

Martinez Santa-Olalla, J., (1946); Esquema paletnológico de la Península lbérica, Madrid.

MENÉNDEZ PIDAL, R., (1952); "Sobre el substrato mediterráneo occidental" y «Ligures o ambroilirios en Portugal', en Toponimia prerromana hispana, Madrid, pp.73-104 y pp.161-178.

Molinero PÉrez, A., (1958); Los yacimientos de la Edad de Hierro en Ávila y sus excavaciones arqueológicas, Avila.

MONSAlUd, M. de, (1901); "Citanias extremeñas", Revista de Extremadura, 3.

montenegro, A., Blazouez, J.M a., Ruiz Mata, D., Garcia Cano, J.Ma., Iniesta, A.. Fatás, G., Salinas, M., PAstor, M., (1989); Historia de España, 2. Colonizaciones y formación de los pueblos prerromanos, Madrid.

POKORNy, J., (1936); "Zur Ugeschichte der Kelten und Illyrier", Zeitschrift für Celtische Philologie, 20, pp.315-351.

POKORNY, J., (1940); "Zur Ugeschichte der Kelten und Illyrier", Zeitschrift für Celtische Philologie, 21, pp.55-101.

Prieto, A., (1979); "El franquisme i la Historia Antiga”, L'Avenc, 18, pp.75-77.

RENFREW, C., (1990); Arqueología y lenguaje. La cuestion de los origenes indoeuropeos, Barcelona.

Rodriguez-Puértolas, J., (1986); Literatura fascista española. I. Historia, Madrid.

Roldán Heqvás, J.M., (1971); Iter ab Emerita Asturicam. El camino de la Plata, Salamanca. 
Roso DE LunA, M., (1901); “Poblaciones celto-lusitanas o citanias cacereñas", Boletin de la Real Academia de la Historia, 28.

Roso De LunA, M., (1904); "Sobre las citanias extremeñas", Boletín de la Real Academia de la Historia, 45, pp.507-510.

Ruiz Zapatero, G., (1985); Los Campos de Urnas del N.E. de la Peninsula lbérica, Madrid.

Ruiz Zapatero, G., (1993); "El concepto de celtas en la Protohistoria europea y española", en Almagro Gorbea, M., (dir.), Los Celtas: Hispania y Europa, Madrid, pp.23-62.

SALINAS DE FRIAS, M., (1979); "Algunos aspectos económicos y sociales de los pueblos prerromanos de la Meseta", Memorias de Historia Antigua, 3, pp.73-79.

Salinas dE FRIAS, M., (1982); La organización tribal de los Vettones. (Pueblos prerromanos de Salamanca), Salamanca.

Sanchez Moreno, E., (e.p.); “La cuestión de los limites y fronteras en los pueblos prerromanos de la Peninsula lbérica: el caso de los vetones y su marco territorial», III Congreso Peninsular de Historia Antigua (Vitoria, 1994).

SÁnChEz MORENO, E., (1995); Historia y Arqueologia de los vetones. Una aproximación critica. Memoria de Licenciatura inédita. U.A.M

SANGSMEISTER, E., (1960); "Die Kelten in Spanien", Madrider Mitteilungen, 1, pp.74-99.

Sayans Castaños, M., (1957); Artes y pueblos primitivos en la Alta Extremadura, Plasencia.

SAYAS ABENGOECHEA, J.J., (1993); "Algunas consideraciones sobre cuestiones relacionadas con la conquista y romanización de las tierras extremeñas", El proceso histórico de la Lusitania oriental en época prerromana y romana, Cuadernos Emeritenses, $n^{9} 7$, Mérida, pp.189-233.

Sayas Abengoechea, J.J., López Melero, R., (1991); "Vettones", en Solana Sainz, J.Ma., (ed.); Las entidades étnicas de la Meseta Norte de Hispania en época prerromana. (Anejos de Hispania Antiqua), Valladolid, pp.75-123.

SCHulE, W., (1969); Die Meseta-Kulturen der Iberischen Halbinsan, 2 vol., Berlin.

SCHulE, W., (1979); "Die Keltiberer archäologisch gesehen", II Coloquio sobre Lenguas y Culturas prerromanas de la Península lbérica (Tübingen, 1976), Salamanca, pp.197-209.

Schulten, A., (1914); Numantia, I, Munich.

Schulten, A., (1922); Avieno. Ora Marítima, Barcelona.

SChulten, A., (1959); Geografia y Etnografia de la Peninsula Ibérica, I y II, Madrid.

SIRET, L., (1934); "Les premiers celtes en Espagne", Anuario del Cuerpo Facultativo de Archiveros, Bibliotecarios y Arqueólogos, 1, pp.85-99.

SOlANA SAINZ, J.Ma.., (1991); "Las entidades étnicas de la Submeseta Septentrional en época prerromana: el marco territorial", en Solana Sainz, J.M"., (Ed.); Las entidades étnicas de la Meseta Norte de Hispania en época prerromana (Anejos de Hispania Antigua), Valladolid, pp.13-38.

StARY, P., (1983); "Keltische waffen auf der Iberischen Halbinsen", Madrider Mitteilungen, 23, pp.114-144.

Taracena, B., (1952); "Los pueblos de la España céltica", en Menéndez Pidal, R., (dir.), Historia de España, 1-3, Madrid, pp.1-299.

TARRADELL, M., (1980); “Primeras culturas. Los pueblos del centro y del norte de la Peninsula", en Tuñón de Lara, M. (dir.). Historia de España, I. Introducción. Primeras Culturas e Hispania Romana. Barcelona, pp.153-169.

TOVAR, A., (1949a); Estudios sobre las primitivas lenguas hispánicas, Buenos Aires.

Tovar, A., (1949b); “Nuevas gentilidades y respuestas sobre el tema de los indoeuropeos en Hispania", Anuales de Filologia Clásica, 4, pp.353-356.

TOVAR, A., (1957); "Las invasiones indoeuropeas, problema estratigráfico", Zephyrus, 8, pp.77-83.

TOVAr, A., (1967); "Lingüistica y arqueología sobre los pueblos primitivos de España", en Gómez Tabanera, J., (ed.), Las raices de España, pp.213-251.

Tovar, A., (1986); "The Celts in the Iberian Peninsula: archaeology, history, languague", en Schmidt, K.H. (ed.), Geschichte und Kultur der Kelten, Heidelberg, pp.68-101.

UNTERMANN, J., (1984); "Los celtíberos y sus vecinos occidentales", Lleters Asturianes, 13, pp.6-26.

UnTERmanN, J., (1987); "Lusitanisch, Keltiberisch, Keltisch", Actas del IV Coloquio sobre Lenguas y Culturas Paleohispánicas (Vitoria, 1985), Vitoria, pp.57-76.

UNTERMANN, J., (1992), "Los etnónimos de la Hispania antigua y las lenguas prerromanas de la Península Ibérica», en Almagro Gorbea, M./Ruiz Zapatero, G., (Eds.), Paleoetnología de la Peninsula lbérica, Madrid, pp.19-33.

VILLAR, F., (1991); Los indoeuropeos y los origenes de Europa. Lenguaje e historia, Madrid 